\title{
A atividade teatral como instrumento para a aprendizagem do PLE no Departamento de Interpretação e Tradução da Universidade de Bolonha, sede de Forlì
}

\begin{abstract}
Resumo:
O teatro ensina a conhecer ansiedades e a geri-las num ambiente protegido, onde subir para um palco ajuda a proteger-se de receios, e a construir uma personalidade mais ampla. A atividade teatral é formativa e é um instrumento de crescimento para todas as idades, durante todas as fases da vida. O laboratório teatral universitário em Forlì, que teve início há vinte e seis anos, é uma experiência extraordinária assim como é um ótimo instrumento didático. Mas pode-se ensinar uma língua estrangeira através duma atividade teatral? E o teatro musical pode servir para ensinar e aprender uma «outra» língua?

Está reconhecido que o laboratório teatral é útil para ensinar não só a literatura ou a dramaturgia, como também a didática das línguas estrangeiras onde estudantes podem experimentar a eficiência de várias técnicas de simulação e dramatização. Há anos que o teatro é o fulcro de uma atividade e um instrumento didático mais do que uma forma de arte por si só. Ensinar através do teatro faz parte de um contexto didático e deixou de ser só uma escolha de um professor cheio de iniciativa e criatividade.
\end{abstract}

Palavras-chave: laboratório teatral, didática das línguas estrangeiras, didática do português como L3, interculturalidade, linguagem teatral 


\begin{abstract}
:
The Theatrical Activity as an Instrument for the Learning of PLE in the Interpretation and Translation Department of the University of Bologna, Headquarters of Forlì

The theater teaches you to know anxieties and manage them in a protected environment, where climbing to a stage helps protect oneself from fears, and builds a broader personality. Theatrical activity is formative and is an instrument of growth for all ages, and during all phases of life. The university theatrical laboratory in Forlì, which began twenty-six years ago, is an extraordinary experience as it is a great teaching instrument. But can a foreign language be taught through a theatrical activity? And can musical theater serve to teach and learn an "other" language?
\end{abstract}

It is recognized that the theatrical laboratory is useful for teaching not only literature or dramaturgy, but also the teaching of foreign languages where students can experience the efficiency of various techniques of simulation and dramatization. For years the theater has been the fulcrum of an activity and a didactic instrument more than an art form alone. Teaching through theater is part of a didactic context, and is no longer just a choice of a teacher full of initiative and creativity.

Keywords: theatrical laboratory, foreign language teaching, Portuguese as L3, interculturality, theatrical language

\title{
Introdução
}

O melhor professor é um dramaturgo. Daniel Pennac

No seguimento do tema sobre o cruzamento e o intercâmbio da língua, cultura e literatura portuguesas na sua expressão teatral gostaria, antes de mais, de apresentar a atividade teatral no âmbito universitário de estudantes italianos, jovens e adultos, que estudam a língua portuguesa como L3, com um único curso semestral no $1^{\circ}$ ano, e anual no $2^{\circ}$ e $3^{\circ}$, junto do Departamento de Interpretação e Tradução da Universidade de Bolonha, sede de Forlì, atividade esta que existe há 26 anos mas o "Grupo de Teatrantes de Português" existe apenas desde 2009. 
O percurso da atividade teatral no departamento DIT da Universidade de Bolonha, na sede de Forlì é muito importante no país, e não só na cidade ou na região, pois vão à cena no mês de maio espetáculos teatrais em 12 línguas diferentes, perfazendo assim o número das línguas que aqui se estudam, e alcançando um total de cerca de 250 atores-participantes.

A prática teatral torna assim possível experimentar e explorar, todas as vezes que o desejamos, algumas das zonas mais escondidas do nosso próprio ser, incluindo aquelas que mais produzem ansiedade e receio porque são por nós consideradas como negativas. Fazer teatro ensina a conhecer estas ansiedades e a geri-las num ambiente protegido no qual a sociedade, os pais e os amigos, limitam a liberdade do comportamento. Subir para um palco por mais pequeno que seja, ajuda a proteger o próprio ser de receios, chegando a conseguir integrá-los no próprio eu de forma a construir uma personalidade mais ampla. Assim sendo, e sem dúvida alguma, a atividade teatral é formativa e é um instrumento de crescimento em todas as idades, durante todas as fases da vida. Nos mais novos torna-se no lugar da descoberta e da possibilidade de ser e fazer muitas outras coisas que de outra forma não seria possível, dado que regras sociais e familiares o impedem, criando um espaço no qual fantasia e criatividade podem exprimir-se com a maior liberdade no seio de um percurso de conjunto, isto é, juntamente com um grupo de pessoas-atores. É no encontro destas duas realidades que nasce o laboratório teatral, considerado como um percurso terapêutico que separa o mundo real daquele possível e fantasioso sem regras, ou melhor, com outras regras, típicas dos ambientes imaginários. Eis o motivo pelo qual neste espaço é mais fácil viver, deixar-se transportar, questionar-se, descobrir-se, inventar-se, relacionar-se com os outros. Este é o ambiente ideal para quem é tímido, para quem tem problemas físicos ou dificuldades na linguagem, para quem tem dificuldades no relacionamento quotidiano seja no mundo real seja naquele escolar ou laboral. É o ambiente ideal porque proporciona liberdade, novos cenários, novas personalidades na tentativa de alcançar um crescimento pessoal íntimo e social, ao mesmo tempo. Claro que este caminho não está de todo livre de obstáculos e de sofrimento, 
pois trata-se de um percurso de passagem de uma passividade inconsciente para uma atividade consciente, dado que se escolhe participar ativamente nele e não se trata de um constrangimento forçado. Chegar a dominar e a enfrentar os próprios receios pode causar, e causa, prazer mas pode ser também um percurso longo e demorado.

O laboratório teatral é aconselhado a todos, desde os mais pequenos até aos adultos em idade avançada, porque além de ser formativo e terapêutico como já o dissemos, desenvolve a personalidade, ajuda no relacionamento, proporciona a criatividade, favorece a formação harmónica e da auto-estima, enriquece o conceito de colaboração, partilha e aceitação do outro e da diversidade, assim como o espírito de iniciativa e, obviamente, a expressão pessoal através da linguagem verbal e corpórea. No laboratório teatral cada um pode ceder a própria personalidade aos outros e passar a ser alguém muito diferente de si próprio, pois um homem pode ser uma mulher e vice-versa, um adulto pode ser uma criança e vice-versa, uma pessoa pode ser um animal .... No laboratório teatral pode-se ser tudo aquilo que a fantasia quiser, e o sentimento frequentemente presente nos adolescentes de inadequação desaparece ao "fingir" ser alguém diferente. No laboratório teatral, ou seja, no palco no fim das contas, a formação do ator não é finalizada à transformação "num outro" eliminando o próprio eu, mas sim tem como objetivo aquele de valorizar as próprias qualidades no respeito da própria personalidade. Se um tímido aceita ser o protagonista e cantar num musical, e claramente ninguém o obriga a fazer isso, é porque ele sente que o pode fazer sem incertezas. Segundo uma visão pedagógica a atividade teatral possui os objetivos que proporcionam e facilitam a comunicação com os outros, a aquisição de uma maior segurança pessoal, a gestão da timidez, a expressão (dicção e fonética corretas), a imaginação, a criatividade, o domínio emotivo, a capacidade de observação, a imitação, a fantasia, o contacto com os outros e o corpo dos outros, e a gestão do próprio corpo e do espaço que o rodeia. Desta forma, o espaço cénico representa simbolicamente o espaço social, e aprender a estar sobre um palco e diante de um público, significa passar a ter conhecimento do próprio espaço na vida e junto aos outros. O objetivo é aquele de estimular as relações interpessoais 
diárias, o conhecimento recíproco, a partilha dos espaços, a cooperação, a descoberta dos tempos - próprio e dos outros - a valorização da heterogeneidade.

O teatro permite alcançar a capacidade de conhecer e gerir com eficácia as próprias emoções, oferecendo assim uma forte dose de auto-estima injetada no momento em que se experimentam outras identidades. Através do teatro conseguem-se enfrentar nós emotivos, conflitos interiores e bloqueios comunicativos, e o jogo da representação teatral torna-se um instrumento útil para tolerar emoções fortes, controlar e viver condições que dificilmente e de outra forma poderão ser superadas, tudo isto tendo em conta que uma certa dose de frustração não é impossível evitar, mas que sem dúvida poderá ser dominada mais facilmente. Mas como começar? E qual poderá ser assim um bom ponto de partida? Normalmente as técnicas utilizadas têm como primordial objetivo aquele de relaxar e abater bloqueios e críticas, pois ao fazer parte de um grupo novo ou de uma nova atividade o risco de "fazer má figura" é constante, e então fazer algumas cenas de improvisação e de jogo ou brincadeira dá de imediato uma sensação de relaxamento e distensão humoral notável. Cenas ou jogos que podem ser exercícios de movimento com o próprio corpo, gestos, comunicação não verbal. Depois passa-se para a parte dos exercícios com a voz para aprender a modulá-la e a utilizá-la da melhor forma, tendo em conta os tons, a intensidade e a potência dos sons, para aprender a correta utilização da respiração e do diafragma. Após a tomada de consciência e de perceção das próprias capacidades, passa-se à apresentação pessoal sentados todos em roda, no chão, para só de seguida poder passar aos exercícios com contato nos outros, ou colaborando com os outros, individualmente ou aos pares. Estas técnicas podem ser usadas com crianças, jovens ou adultos, com pessoas de todas as idades dado que as problemáticas apresentadas se encontram em qualquer fase da vida e em qualquer idade. Por exemplo, são práticas utilizadas como momento de integração de alunos muito pequenos quando vão para o infantário pela primeira vez, abandonando o próprio lar, algumas vezes sem o compreenderem muito bem e considerando-o até mesmo uma violência; ou então usam-se estes jogos para a integração de 
alunos em ambientes escolares novos ou desconhecidos, se provêm de outros países.

\section{A atividade teatral em língua portuguesa no DIT}

Há anos que o teatro faz parte, e é, ao mesmo tempo, o fulcro de uma atividade predominantemente interessada a ser um instrumento didático mais do que uma forma de arte por si só. Em vários países espalhados por este mundo fora, ensinar através do teatro faz parte de uma reforma assimilada também pelas instituições e já não é só, e apenas, uma escolha de um professor cheio de iniciativa e criatividade. Está reconhecido que o teatro é útil para ensinar não só a literatura como também outras artes, e o uso do laboratório teatral num contexto de didática das línguas num ambiente universitário, sobretudo das línguas estrangeiras como L2 onde o estudante pode experimentar através de exercícios práticos a eficiência de técnicas como simulação, role play, role taking, role making, dramatização, etc., está reconhecido como fundamental.

A atividade teatral em língua portuguesa no DIT começou em 2009 no seguimento do interesse de um grupo de estudantes dos vários cursos de língua portuguesa, os quais já fazendo parte há alguns anos desta atividade, e tomando parte noutros espetáculos e noutras línguas, sentiram a necessidade, e a oportunidade ideal, de criarem um espetáculo também em português. Assim sendo, e partir do ano letivo de 2009-2010 até hoje, muitos foram os espetáculos escritos e preparados prontos para serem recitados. O primeiro foi Falar verdade a mentir, a comédia de Almeida Garrett, que foi representada na sua integridade, em português, e a rigor de encenação e vestuário. Foram apenas incluídas algumas gags para uma maior compreensão do texto. Número de participantes entre atores e técnicos: 15

Em 2010/11 foi realizada uma nova versão do filme americano que tinha como protagonista a atriz Julie Andrews, A música no coração (musical), traduzindo as canções e introduzindo novas coreografias. Foi pela primeira vez projetada a legendagem em italiano. Número de participantes entre atores e técnicos: 12 
Em 2011/12 foi a vez de Pílulas de Sslmit (musical), um texto completamente novo e ambientado na época moderna e na cidade de Forlì, onde foram apresentadas as problemáticas típicas dos estudantes desta faculdade. Foram introduzidas algumas canções retiradas de vários desenhos animados da Walt Disney, adaptadas e traduzidas para a língua portuguesa, com relativas coreografias. Número de participantes entre atores e técnicos: 19

Em 2012/13 O amor é um horror (musical) era o título do remake do filme de 1975 do realizador Jim Sharman, Rocky Horror Picture Show, que por sua vez tinha sido feito a partir do espetáculo teatral com o mesmo nome, e de 1973, da autoria de Richard O'Brien. Foi a partir deste espetáculo que todas as nossas peças passaram a terminar com um bailado final, todos juntos, tal como o final dos filmes da indústria cinematográfica indiana de Bollywood. Número de participantes entre atores e técnicos: 20

Em 2013/14 foi a vez de A qualcuno piace Vasco (musical) imaginado após a visão do filme de 1933, realizado por José Cottinelli Telmo, e que inaugura o género cinematográfico - a comédia à portuguesa. Este espetáculo refaz novamente $A$ Canção de Lisboa, num ambiente mais moderno e com mais personagens, pois o grupo era númeroso. A partir deste espetáculo todos os textos foram integralmente representados em língua, com legendas projetadas. Número de participantes entre atores e técnicos: 29

Em 2014/15 foi interpretado Um sonho maravilhosamente louco (musical) para celebrar os 150 anos da obra "As aventuras de Alice no país das maravilhas" de Lewis Carroll, e foi assim realizado um espetáculo cómico e musical utilizando as canções do grupo sueco ABBA. Número de participantes entre atores e técnicos: 35

No ano letivo 2015/16 subiu ao palco Fado, Alface e Fantasia (musical), um texto completamente inédito com base histórica para recordar não só a história do Fado e da sua mais célebre fadista, Amália Rodrigues, como também para dar a conhecer ao público italiano, num percurso sistemático, um pouco mais da época do fascismo com as suas proibições. A ação começa em 1924, em Macau, com Amália pequena que canta um fado e a avó que a proíbe. A neta, não aceitando 
esta proibição pede à avó que lhe conte por que motivo teve de abandonar Portugal, e deixar de cantar o fado. Na segunda cena a ação passa para os anos 70, numa pequena aldeia chamada Carne Assada, onde um despótico Presidente da Câmara proíbe que se cante o fado. É assim organizado um concurso de talentos - "Carne Assada Tem Talento" - na tentativa de conquistar a possibilidade de se voltar a cantar o fado. Número de participantes entre atores e técnicos: 30

No ano letivo de 2016/17, após os alunos terem visto o filme "A Gaiola Dourada" do realizador Ruben Alves, do qual gostaram muito, nasceu assim a adequada inspiração para criarem um novo espetáculo musical que teve como base o tema da emigração portuguesa em França. Um prédio português foi o título escolhido para apresentar quatro histórias relativas às quatro famílias que moravam nos vários andares, começando por uma porteira portuguesa que tinha regressado a Portugal, após vários anos a prestar serviço em Paris, e o seu bom relacionamento com as várias famílias que ali viviam; havia também um grupo de estudantes veganos, duas terríveis crianças e a sua exigente babysitter, a senhora dos gatos e o seu problema com a ginjinha, e as duas solteironas apaixonadas por Cristiano Ronaldo. No meio de todas estas problemáticas ,reais” havia a presença de duas freiras misteriosas que queriam vender a Igreja da Nossa Senhora do Loreto (a igreja dos italianos) em Lisboa. A visita da porteira aos vários apartamentos serviu também como pretexto para a apresentação de vários temas da tradição portuguesa, tais como, a emigração, a religiosidade, a gastronomia regional, a doçaria conventual, a origem do vinho do Porto, a lenda da sopa da pedra e as formas de tratamento. Número de participantes entre atores e técnicos: 24.

E chegamos assim ao espetáculo mais recente, em maio de 2018, cujo título é "Engarrafados”. Partimos da visão do filme „Dot.com” de Luís Galvão Teles, que trata o tema da ,invasão” espanhola e da rivalidade com a Espanha entre populações fronteiriças. Jogando com os trocadilhos, as maneiras de dizer, as expressões, os clichés e as tradições dos dois países, o espetáculo foi escrito contemplando três línguas: português, espanhol e italiano. Número de participantes entre atores e técnicos: 16 
Em todos os espetáculos o texto foi escrito em grupo, assim como as letras das canções que adquiriram uma forma original e adequada ao tema do espetáculo; foi feita a legendagem em italiano e a sua projeção para o público que normalmente ronda as 500 pessoas.

\section{O teatro como instrumento didático para o PLE L3}

Mas o teatro pode ser, na verdade e efetivamente, um instrumento didático? Pode-se ensinar uma língua estrangeira através duma atividade teatral? O teatro musical pode servir para ensinar e aprender uma "outra" língua? Podemos concluir que sim, pois através desta apresentação dos espetáculos desde os seus primórdios, compreende-se a importância da atividade teatral na didática das línguas estrangeiras, pois todos os alunos tiveram um papel linguístico, isto é, houve quem escreveu os diálogos e dividiu as cenas, quem corrigiu o texto, quem traduziu as canções e as adaptou, quem fez a legendagem, quem se ocupou da narração e das deixas, quem delineou os espaços, as personagens e a situação inicial, quem deu um cariz satírico e humorístico ao texto, quem realizou e ensinou as coreografias, ocupando-se também do espaço cénico, quem fez a maquilhagem e a roupa de cena, mas ninguém deixou de se sentir importante e parte integrante do espetáculo. Ao preparar um espetáculo, o texto, ou os textos, são escritos, adaptados e/ou traduzidos num exercício dinâmico e constante do estudo de uma língua e da sua cultura. O teatro, neste sentido, pretende ser um instrumento didático na aprendizagem das competências tradutivas linguísticas interculturais. O teatro musical e, acrescentaria, cómico, é sem dúvida importante pois permite memorizar palavras novas, aumentando o próprio léxico, juntamente com a pronúncia correta, até mesmo em pessoas que nunca estudaram a língua estrangeira antes. De facto, várias vezes fizeram parte dos espetáculos em língua portuguesa pessoas que nunca tinham estudado até àquele momento esta língua.

$\mathrm{O}$ teatro com as suas técnicas próprias favorece assim a aprendizagem e a estabilização das línguas estrangeiras, pois graças à magia e à interação espontânea ou dirigida, os participantes deixam-se naturalmente levar, usando expressões e termos aprendidos sem terem 
medo de cometer erros ${ }^{1}$. Este percurso deve obviamente ser introduzido por alguns exercícios que estimulam a própria confiança no interior do grupo, para que a improvisação e o uso, por vezes exagerado, de gestos e aspetos prosódicos típicos da cultura de chegada, faça com que os alunos-atores adquiram o estado mental ideal e, acrescentaria, perfeito, para poderem assim resolver todas as situações "teatrais" numa língua que não é a própria. Assim sendo, o sucesso está garantido, pois quem mais participa, mais se diverte. A par desta atividade teatral feita ao serão, e após o horário das aulas, durante as mesmas deverão estar incluídas atividades adequadas ao aprofundamento de objetivos tais como os seguintes: fornecer conhecimentos sobre a dramaturgia portuguesa contemporânea e enquadrá-la nas modernas correntes da escrita de teatro; treinar a análise do texto de teatro; abordagem da língua e da cultura portuguesas; a dupla articulação entre dramaturgia e sociedade e entre texto de teatro e espetáculo; exercitar a pesquisa documental sobre textos, autores e espetáculos. Sem esquecer adequados e importantes conteúdos programáticos como a re-interpretação e a apropriação de temas clássicos; o lugar do teatro na História; o teatro dramático e pós-dramático; a tipologia das várias personagens; a voz poética e a descontinuidade narrativa.

O que é então o teatro, sobretudo o teatro em língua estrangeira? Certamente é a arte de falar caracterizada pela confluência das diversas linguagens, pela efemeridade das suas práticas e pela repercussão social que possui. É um discurso composto por palavras e gestos que traduzem pensamentos e imagens. É, em suma, a descoberta da tradução da voz dos outros, e as suas palavras-chave são:

- expressão dramatúrgica

- atividade teatral

- didática das línguas estrangeiras

- laboratório pedagógico, didático e linguístico

- cruzamento e intercâmbio literário e linguístico-cultural numa única palavra: Alquimia, porque $O$ teatro é mais honesto que o cinema, porque o cinema filma sonhos. O cinema é imaterial,

\footnotetext{
${ }^{1}$ com referência também às regras usuais do process drama.
} 
o teatro é material: os actores têm carne e osso, estão lá, vivos, nos cenários. Mas o cinema, não - é um fantasma da realidade. O teatro é mais rico. Os actores estão lá, em carne e osso. No cinema, só está a personagem. O actor já não se encontra lá quando o filme é exibido. O cinema é complementar mas tem uma vantagem: perdura no tempo. - Manoel de Oliveira, entrevista pelo seu $99^{\circ}$ aniversário ${ }^{2}$.

\section{O teatro como um jogo emotivo e um instrumento didático para o PLE}

O teatro é a arte de falar caraterizada pela confluência de diversas linguagens, pela efemeridade das suas práticas e pela repercussão social que possui. É um discurso composto por palavras e gestos que traduzem um pensamento e imagens metafóricas. É um laboratório interdisciplinar para a aquisição de competências transversais (soft skills) e as competências específicas no âmbito do processo de aquisição da língua estrangeira para futuros mediadores linguísticos interculturais. É o desenvolvimento da competência comunicativa intercultural, da competência etnoempática, e a estabilização do património literário, teatral e cultural. $\mathrm{O}$ teatro permite alcançar a capacidade de conhecer e gerir com eficácia as próprias emoções, oferecendo assim uma forte dose de auto-estima injetada no momento em que se experimentam outras identidades. Através do teatro conseguem-se enfrentar nós emotivos, conflitos interiores, e bloqueios comunicativos, e o jogo da representação teatral torna-se num instrumento útil para tolerar emoções fortes, controlar e viver condições que dificilmente e de outra forma poderão ser superadas, tudo isto, tendo em conta que uma certa dose de frustração não é impossível evitar, mas que sem dúvida poderá ser dominada mais facilmente. E como começar? Qual poderá ser um bom ponto de partida? Normalmente as técnicas utilizadas têm como primordial objetivo aquele de relaxar e abater bloqueios e críticas, pois ao fazer parte de um grupo novo ou de uma nova atividade o risco de "fazer

${ }^{2}$ Encontra-se em: http://www.rainews.it/dl/rainews/media/Oliveira-intervistato-dal-TG1.-6bfb7359-f8ae-4ab7-83b3-a05d88f942d8.html e em https:// pt.jarofquotes.com/perfil/porque $\% 20 \mathrm{o} \% 20$ cinema $\% 20$ filma/. 
má figura" é constante, e então fazer algumas cenas de improvisação e de jogo ou brincadeira dá de imediato uma sensação de relaxamento e distensão humoral notável. Cenas ou jogos que podem ser exercícios de movimento com o próprio corpo, gestos, comunicação não verbal. Depois passa-se para a parte dos exercícios com a voz para aprender a modular e a utilizá-la da melhor forma, tendo em conta os tons, a intensidade e a potência dos sons, para aprender a correta utilização da respiração e do diafragma. Após a tomada de consciência e de perceção das próprias capacidades, passa-se à apresentação pessoal sentados todos em roda no chão, para só de seguida poder passar aos exercícios com contacto nos outros, ou colaborando com os outros ou aos pares. Estas técnicas podem ser usadas com crianças, jovens ou adultos, com pessoas de todas as idades dado que as problemáticas apresentadas se encontram em qualquer fase da vida e em qualquer idade. Podemos assim compreender que através da apresentação dos espetáculos desde os seus primórdios, a importância da atividade teatral na didática das línguas estrangeiras, pois todos os alunos tiveram um papel linguístico, e ao preparar um espetáculo, o texto ou os textos são adaptados e/ ou traduzidos num exercício dinâmico e constante de estudo de uma língua e da sua cultura. $O$ teatro neste sentido pretende ser um instrumento didático na aprendizagem das competências tradutivas linguísticas interculturais. O teatro musical e, acrescentaria, cómico (pois rir faz bem!), é sem dúvida importante pois permite memorizar palavras novas, aumentando o próprio léxico, juntamente com a pronúncia correta, até mesmo em pessoas que nunca tinham estudado a língua estrangeira antes. De facto, várias vezes fizeram parte dos espetáculos em língua portuguesa pessoas que nunca tinham estudado até àquele momento esta língua. Este percurso deve obviamente ser introduzido por alguns exercícios que estimulam a própria confiança no interior do grupo para que a improvisação e o uso, por vezes exagerado, de gestos e aspetos prosódicos típicos da cultura de chegada, faça com que os alunos-atores adquiram o estado mental ideal e, acrescentaria, perfeito, para poderem assim resolver todas as situações "teatrais" numa língua que não é a própria. Assim sendo, o sucesso está garantido, pois quem mais participa, mais se apercebe dos benefícios que tal 
atividade fornece, e que poderá igualmente ser o conhecimento sobre a dramaturgia portuguesa, o treino da análise de texto, a abordagem da cultura portuguesa na ótica da dupla articulação entre dramaturgia e sociedade, e entre texto teatral e espetáculo musical, o exercício da pesquisa bibliográfica e documental de textos, autores e espetáculos vindo até a sugerir uma continuação do estudo através da elaboração de teses finais de licenciatura sobre estas temáticas.

\section{Metodologia didática, elementos de inovação e objetivos de aprendizagem}

A metodologia didática diferencia-se pela abordagem olística (total) e etnográfica aplicada à aprendizagem das línguas estrangeiras. Uma abordagem que recorda e reconduz ao modelo do "falante intercultural" (Kraviski e Bergmann, 2006) e ao modelo de Arnold (2000): a dimensão afetiva influi no processo de aquisição da língua estrangeira, porque conhecimento e afetividade são duas esferas que interagem constantemente entre elas. $\mathrm{O}$ filtro afetivo estimula a motivação e faz com que o falante intercultural possa refletir sobre a própria identidade, apesar de se encontrar, e isto é um paradoxo, numa situação que o obriga a assumir variadas identidades ou personagens. Em relação à aula tradicional o estudante-ator pode assim descobrir características escondidas da sua própria personalidade, e além disto, a metodologia ajuda a diminuir a ansiedade que muitas vezes bloqueia a aprendizagem e que, por vezes, pode dar azo a frustração e medo. A metodologia didática é assim aplicada tendo em conta os seguintes objetivos:

- Tradução: os estudantes tomam ulteriormente consciência do facto de que não existe uma única solução para resolver os problemas da tradução, no seguimento daquele aumento da flexibilidade mental de que já falámos. Na fase da construção do texto dramático, recorre-se muitas vezes às técnicas da documentação, manipulação textual e reescrita, onde tudo isto contribui para o desenvolvimento da criatividade estimulada também pela leitura multi-sensorial do texto original. No caso da língua portuguesa, e apenas no primeiro espetáculo, foi usado um texto já existente em português, enquanto que em todos os outros 
espetáculos foi escrito um texto novo e original, no qual, por vezes, os alunos escreveram inicialmente em italiano e depois auto-traduziram-no para português.

- Mediação oral e Interpretação dialógica: no seguimento da aprendizagem cooperativa os estudantes são incentivados a gerir conflitos e a ultrapassar estereótipos ou lugares-comuns culturais. A flexibilidade mental estimulada durante as atividades propostas, favorece uma maior rapidez na passagem de um código linguístico para outro. Nas conversas cara-a-cara aumenta-se o conhecimento da comunicação não verbal e dos elementos que a caraterizam. Os estudantes tomam maior consciência do ritmo, e do tempo conversacional.

- Interpretação consecutiva: graças aos laboratórios teatrais os estudantes exercitam-se sistematicamente nas técnicas para falarem em público (controlo do contato visual, gestualidade, postura, uso da voz, etc.) e aprendem a gerir a comunicação não verbal, refletindo, e ao mesmo tempo, sobre a importância do entrar em empatia com o orador e do desenvolvimento da audição ativa.

- Interpretação simultânea: os estudantes exercitam o uso da voz com profissionalismo, aperfeiçoando a capacidade articulatória. Os exercícios propostos têm a intenção de, por um lado, desenvolver a concentração, o ponto de partida imprescindível para a atenção e para reduzir o "stress da cabine" e, por outro, estimular a flexibilidade e a criatividade necessárias para resolver as dificuldades linguísticas em tempo real.

- Objetivos linguísticos: a estreita relação entre som e gesto, ou seja, a prosódia audiovisual; o desenvolvimento da perceção e da produção holística (total) do fenómeno comunicativo com um contato do tipo multisensorial para a leitura; desenvolvimento da competência prosódica: "o teatro é um instrumento valioso para a aquisição da prática e do aperfeiçoamento da componente da entoação numa Língua Estrangeira; vestindo uma máscara é mais fácil perder a timidez, perder o medo de falar, de errar, de sentir-se ridículo" (Hidalgo Navarro, Cabedo Nebot, 2012).

\footnotetext{
3 Trad. A. F.
} 


\section{Alguns exemplos}

De seguida, apresentam-se alguns exemplos extraídos dos textos teatrais escritos pelos alunos-atores:

1 - o uso da gíria:

"P: Nada! Agora eu tenho que ir embora porque tenho um assunto para tratar, a senhora faz favor não ponha a música alta.

J: Mas que maneiras! até logo!

H: Bom dia!

P: Bom dia, o tanas! Por acaso a senhora viu duas freiras?

H: Freiras?

P: Não faz mal, eu vou à procura delas sozinha."

2 - “(...) Ruperto Pancrácio: Sim, mas... não vejo os telejornais... Vi alguma coisa há poucos dias, mas ao ouvir o nome de Águas Altas só pude pensar em ti! (com cara de parvo) Além disso, eu não sei nada dos negócios da minha mãe, nunca falámos do trabalho dela...

Adriana (chateada): És um ganda parvo! Os negócios da tua mãe tocam-te, tocam-NOS! Se estás a falar verdade então és mesmo um inconsciente... Se na verdade sou importante para ti, deverias fazer alguma coisa!"

3 - Neologismos e uso dos diminutivos:

„Freiras Maria e Fátima: Bom diaaaa!

Freira Fátima: Eu sou a Freira Fát.... Ooooh que gatinhos tão bonitinhosss!!

Freira Maria: Ehm bom dia minha senhora, eu sou a Freira Maria e esta freira tão pirosa chama-se Fátima.

Senhora dos Gatos: (emocionada) AH! Bomdiazinho! Entrem entrem! Um café? (Empurrando as duas) Freira Fátima: Ehhh, então? um cafézinho? Fátima Maria: Não, não, obrigada, mas não viemos aqui para um banquete. Estamos aqui porque.....

Senhora dos Gatos: Talvez gostem de um pouco ginjinha?

Freira Fátima: Não sei o que é mas deve ser boa porque rima com gostosinha! Então ...." 
4 - Referências culturais:

„Freira Maria: (irritada) A Senhora é realmente encantadora e os seus bichos são adoráveis mas o que estávamos a tentar dizer é que nós estamos aqui para arrecadar fundos para a célebre Igreja de Nossa Senhora do Loreto, a Igreja dos Italianos em Lisboa.

Senhora dos Gatos: Nunca na minha vida tinha ouvido sobre esta Igreja. E porquê estes italianos têm uma Igreja aqui em Portugal? Ah pois, na verdade é porque estão por todo o lado!

Freira Fátima: A devoção a Nossa Senhora do Loreto foi trazida para Portugal pelos comerciantes italianos, daí que a Igreja seja também conhecida por Igreja dos "Italianos".

5 - Trocadilhos:

„Senhora dos Gatos: Portanto, se não quer um café, vou trazer uma boa chávena de chá para si, dado que acabei de o preparar para as freiras! Talvez goste também de um pouco de croquetes?

Porteira: O QUÊÊÊ?

Senhora dos Gatos: esparguetes! Quero dizer esparguetes! Que cabeça a minha!"

6 - Provérbios:

"Freira Maria: Por amor de Deus, não é possível!

Senhora dos gatos: Como diz?

Freira Maria: Nada nada, peço desculpa. (olhando para a Irmã Fátima e sussurrando-lhe ao ouvido) Parece-me que nem neste apartamento querem comprar gato por lebre!!"

7 - Uso das formas de tratamento:

"Mary Poppins: meninos! Basta! Parem de correr! A confusão que estão a fazer já chega!! Agora ponham em ordem todos os jogos que vocês atiraram para todo o lado!

Menina: Uuuuu! Nunca nos podemos divertir!! Tu és má! 
Mary Poppins: Teresa, quantas vezes tenho que repetir isto? Com os adultos tem sempre que tratar por você!

Menina: Uuuu! Nunca nos podemos divertir!!! Você é má!

Mary Poppins (satisfeita): Agora está muito melhor!!”

8 - Canção com texto adaptado para a apresentação das formas de tratamento:

"Se faz favor, muito obrigado

Não é tão complicado

Pedir desculpa se formos incorretos

Refrão: Porque o mundo é melhor quando temos boas maneiras temos boas maneiras, temos boas maneiras, Sim, o mundo é melhor quando temos boas maneiras

Um sorriso tudo pode melhorar

Agora tenham de ouvir

O que nós vamos dizer:

As boas maneiras temos de lembrar.

Digam bom dia e não perguntem a idade às senhoras, de outra maneira sem tablet por um mês (...)"

9 - Adaptação da letra da canção "Happy" de Pharrell Williams (2013) cujo título passou a ser: Se estás com sede.

Sobre um comboio que vai pra Coimbra

Está muito quente, 100 graus à sombra

Não tenho água fria pra beber

Mas aqui Ibericah estão a oferecer.

Se estás com sede

Bebe a água de Águas Altas, não te vais arrepender

Se estás com sede

Bebe a água de Águas Altas e vais-te surpreender

Se estás com sede 
Hidratado e feliz seja outubro ou seja abril

Se estás com sede

Bebe a água Ibericah e vais ficar a mil

Num escritório na cidade de Sintra

Está um tradutor que se desconcentra

Não arranja termos para explicar

Que apenas Ibericah pode refrescar

Se estás com sede

Bebe a água de Águas Altas, não te vais arrepender

Se estás com sede

Bebe a água de Águas Altas e vais-te surpreender

Se estás com sede

Hidratado e feliz seja outubro ou seja abril

Se estás com sede

Bebe a água Ibericah e vais ficar a mil.

\section{Concluindo}

O reconhecimento e a apreciação manifestados por parte dos estudantes ao longo destes anos de atividade, acompanhado pelo sucesso no percurso realizado pelos próprios estudantes-atores naquela que, à primeira vista, poderia parecer apenas uma mera atividade lúdica, tornou-se assim uma parte integrante do curriculum formativo dos mesmos, com repercussões transversais que permitem transformar as capacidades desenvolvidas durante os laboratórios teatrais, em habilitações profissionalizantes. Um dado significativo a notar é aquele que nos últimos anos aumentaram, a par e passo, os estágios e as teses com temáticas sobre a atividade teatral, permitindo assim afirmar, convictos, que o teatro em língua estrangeira é a arte de falar caracterizada pela confluência de diversas linguagens, pela efemeridade das suas práticas e pela repercussão social que possui. É um discurso composto por palavras e gestos que traduzem um pensamento e imagens. É, em suma, 
a descoberta da tradução da voz dos outros através da fraseologia das emoções. O teatro em língua estrangeira é assim a arte de falar diante de um público que na maioria das vezes não conhece aquela língua. É um percurso pessoal e coletivo, é um laboratório vivo, um momento de integração do valor afetivo e motivacional, das inteligências múltiplas, da comunicação não verbal, do pensar por imagens e da prosódia audiovisual. É o desenvolvimento da competência etnoempática, da comunicativa intercultural, da flexibilidade mental, da integração de novas linguagens digitais-informáticas-eletrónicas, da aprendizagem colaborativa de uma nova disciplina transversal.

\section{Referências bibliográficas}

ARNOLD, J. (2000), La dimensión afectiva en el aprendizaje de idiomas, Cambridge University Press, Madrid, [on-line] https://cvc.cervantes.es/ ensenanza/biblioteca_ele/antologia_didactica/claves/arnold.htm.

HIDALGO NAVARRO, A., CABEDO NEBOT, A. (2012), La enseñanza de la entonación e nel aula de ELE, Arco Libros, Madrid.

KRAVISKI, E. R., BERGMANN, J. (2006), "Interculturalidade e motivação na aprendizagem de línguas estrangeiras", Revista Intersaberes, 1(1), pp. 78-86, [on-line] https://www.uninter.com/intersaberes/index.php/revista/ article/viewFile/88/62.

\section{Bibliografia consultada}

FERNÁNDEZ García, M. I., BISCU, M. G. (2005/2006), “Theatre in the Acquisition of Intercultural Communicative Competence: The Creation of a Multilingual Corpus of Dramatic Texts for the Training of Future Language Mediators", International Journal of Learning, 12, pp. 327-335, https://www.doi.org/10.18848/1447-9494/CGP/v12i10/48217.

FERNÁNDEZ GARCÍA, M. I., ZUCCHIATTI, M.-L., BISCU, M. G. (orgs.) (2009), L'esperienza teatrale nella formazione dei mediatori linguistici e culturali, BUP, Bologna.

GIRAD, D. (1976), As línguas vivas - ensino e pedagogia, Livraria Almedina, Coimbra.

LEMOS, H. (2000), Comúnicar em Português, Lidel, Lisboa. 